\begin{tabular}{|c|l|}
\hline Title & $\begin{array}{l}\text { INTERMEDIATE OF HOMOMOLECULA R OXY GEN EX CHA NGE REACTION AT LIQUID NITROGEN } \\
\text { TEMPERATURE }\end{array}$ \\
\hline Author(s) & TANA KA, Ken-ichi \\
\hline Citation & JOURNAL OF THE RESEARCH INSTITUTE FOR CA TALYYSIS HOKKA IDO UNIVERSITY, 23(3), 171-175 \\
\hline Issue Date & 1976-06 \\
\hline Doc URL & http://hdl.handle.net/2115/24999 \\
\hline Type & bulletin (article) \\
\hline File Information & 23(3)_P171-175.pdf \\
\hline
\end{tabular}

Instructions for use 


\title{
INTERMEDIATE OF HOMOMOLECULAR OXYGEN EXCHANGE REACTION AT LIQUID NITROGEN TEMPERATURE
}

\author{
By \\ Ken-ichi TANAKA*) \\ (Received November 18, 1975)
}

\begin{abstract}
The homomolecular oxygen exchange reaction reaction takes place far more rapidly at liquid nitrogen temperature than at room temperature over $\mathrm{ZnO}$ and on $\mathrm{TiO}_{2}$. The super oxide ions adsorbed on these oxides do not take part in this low temperature exchange reaction. In this paper, a neutral $\mathrm{O}_{4}$ intermediate is infered for this low temperature exchange reaction instead of the $\mathrm{O}_{4}^{-}$having been proposed in the referrnces.
\end{abstract}

In these several years, the three forms of adsorbed oxygen species, $\mathrm{O}^{-}, \mathrm{O}_{2}^{-}$and $\mathrm{O}_{3}^{-}$, have been firmly established by using ESR technique ${ }^{1)}$, and now our interesting is focussing on the reactivity and/or the selectivity of these species in the catalytic oxidation reactions.

The author has shown that $\mathrm{O}^{-}$is the reactive intermediate of the catalytic oxidation of $\mathrm{CO}$ on $\mathrm{ZnO}$ in dark and under illunination ${ }^{2,3)}$ and $\mathrm{O}_{2}^{-}$on the $\mathrm{ZnO}$ or $\mathrm{TiO}_{2}$ is less reactive for the oxidation reactions as well as for the isotopic exchange reactions with $\mathrm{CO}$ and $\mathrm{O}_{2}{ }^{4}{ }^{4}$ NACCACHE ${ }^{5 /}$ has also shown the high reactivity of $\mathrm{O}^{-}$on $\mathrm{MgO}$ for $\mathrm{O}_{2}, \mathrm{CO}$ and $\mathrm{C}_{2} \mathrm{H}_{4}$. The author ${ }^{9}$ has found that a small amount of $\mathrm{CO}$ inhibites strongly the homomolecular oxygen exchage reaction on $\mathrm{ZnO}$ under illumination, which make us to propose $\mathrm{O}_{3}^{-}$intermediate for the exchange reaction under illumination, ${ }^{8,9)}$ that is, the higher reactivity of $\mathrm{O}^{-}$with $\mathrm{CO}$ than that with $\mathrm{O}_{2}$ disturbes the formation of $\mathrm{O}_{3}^{-}$. This paper gives the evidences showing other intermediate for the homomolecular oxygen exchange reaction taking place at liquid nitrogen temperature in dark.

\section{Experimental}

$\mathrm{ZnO}$ of $0.43 \mathrm{~g}$ (Kadox-25 from New Jersey Zinc Co.) and rutile type $\mathrm{TiO}_{2}$ of $0.55 \mathrm{~g}$ (Titanox RA-10 from Titanium Pigment Co.) were used as

*) Research Institute for Catalysis, Hokkaido University, Sapporo, Japan. 


\section{K. TANAKA}

catalyst. These oxides were treated with oxygen at $410 \sim 420^{\circ} \mathrm{C}$ for several hours and were evacuated for more than 12 hours at the same temperature. After the evacuation, the catalyst was cooled in vacuum and was subjected to the experiments.

The isotopic analysis of gas phase oxygen as well as the desorbed oxygen were carried out by connecting the reactor directly to the mass spectrometer.

Oxygen-18 (ca. 90 atom \%) from YEDA R \& D Co. and Oxygen-16 from Takachiho Kagaku Kogyo were used without further purification.

\section{Results and Discussion}

A mixture of ${ }^{16} \mathrm{O}_{2}$ and ${ }^{18} \mathrm{O}_{2}$ of 0.6 torr was admitted to the zinc oxide at room temperature. Homomolecular exchange reaction over zinc oxide at room temperature was too slow to measure the reaction, and few exchange reaction took place even after 8.5 hours.

The rate of the equilibration, however, substantially increased at liquid nitrogen temperature, and the gas phase composition arrived to about $74 \%$ of the equilibration within 30 minutes as shown in Figure 1. After the evacuation of the gas phase oxygen at liquid nitrogen temperature, the

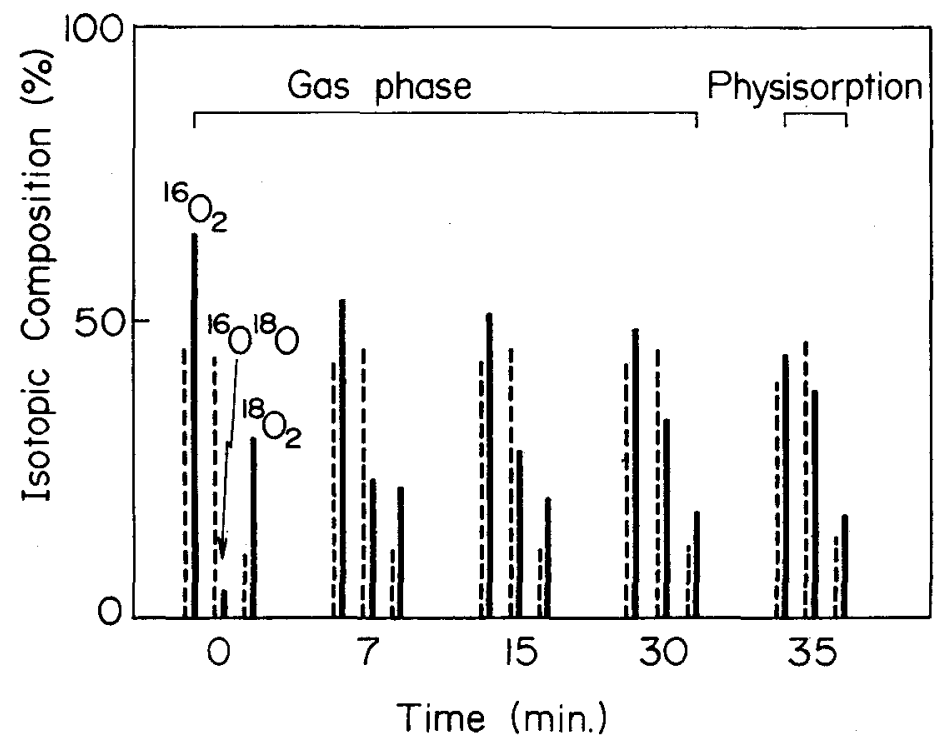

Fig. 1. The isotopic equilibration, ${ }^{16} \mathrm{O}_{2}+{ }^{18} \mathrm{O}_{2} \leftrightharpoons 2{ }^{16} \mathrm{O}^{18} \mathrm{O}$, on $\mathrm{ZnO}$ at liquid nitrogen temperature.

Dotted lines are the calculated equilibrium compositions. 
reactor was warmed to room temperature to make the analysis of the weakly adsorbed oxygen. The isotopic composition of the desorbed oxygen between liquid nitrogen temperature and room temperature is shown in Figure 1 as the physisorbed oxygen. It is obvious that the oxygen desorbed between liquid nitrogen temperature and room temperature is more close to the equilibrium composition than the gas phase oxygen having been evacuated at liquid nitrogen temperature. Where the time of 35 minutes on abscissa indicates that about 5 minutes was required to warm up the reactor from liquid nitrogen temperature to room temperature. In the previous paper, it has been shown that the oxygen adsorbed on the evacuated $\mathrm{ZnO}$ or on $\mathrm{TiO}_{2}$ gives a desorption spectrum having a maximum at around $180^{\circ} \mathrm{C}$, which has been assigned as super oxide ion, $\mathrm{O}_{2}^{-}$, by ESR.

In order to throw light on the participation of the $\mathrm{O}_{2}^{-}$upon the isotopic exchange reaction at liquid nitrogen temperature, the isotope analysis of the desorbed oxygen was made by rising the reactor's temperature, and was compared with the isotopic composition of the gas phase oxygen in the following experiments. About 1 torr of ${ }^{18} \mathrm{O}_{2}$ was admitted to the zinc oxide on which ${ }^{16} \mathrm{O}_{2}^{-}$had been previously prepared at room temperature by

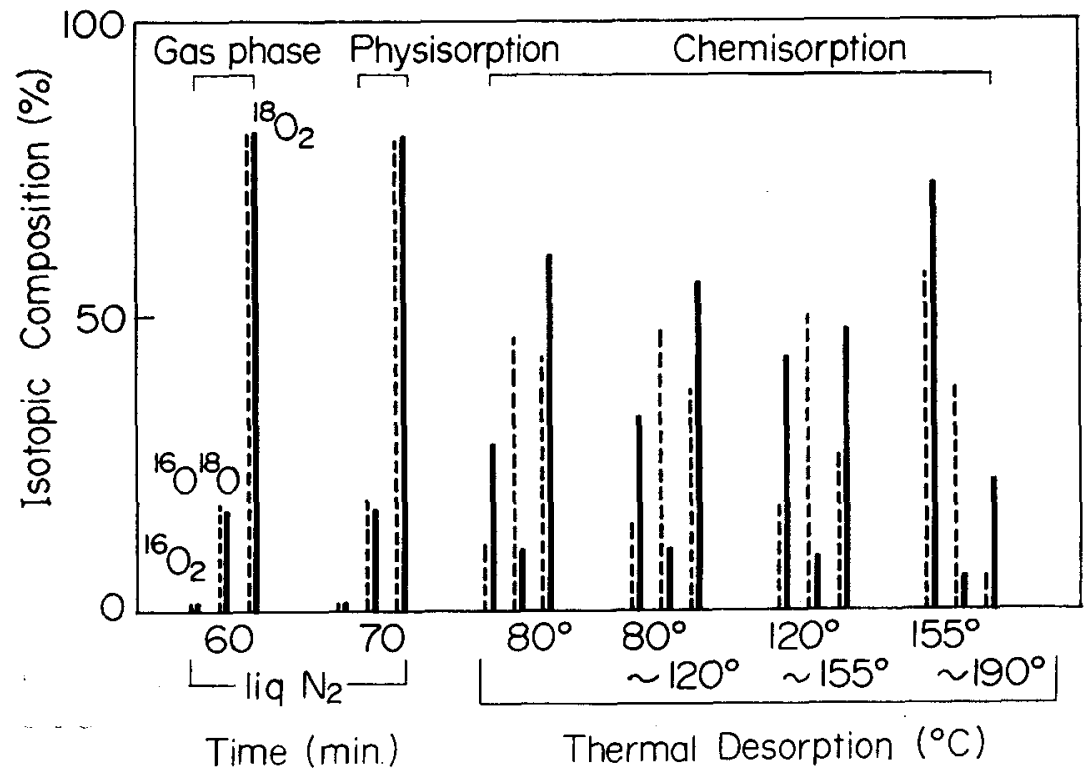

Fig. 2. Isotopic mixing between adsorbed ${ }^{16} \mathrm{O}_{2}^{-}$and gas phas ${ }^{18} \mathrm{O}_{2}$ at liqid nitrogen temperature, and the isotopic distribution in the desorbed oxygen $\left[\mathrm{O}_{2}^{-}\right]$.

Dotted lines are the calculated equilibrium compositions. 
contacting with ${ }^{16} \mathrm{O}_{2}$. About one minutes later, the reactor was cooled to liquid nitrogen temperature and kept it at that temperature for 60 minutes, which is sufficient time to detect the isotopic exchange at liquid nitrogen temperature if occurs as is known from Figure 1. The isotopic composition of the gas phase oxygen as well as that of the physisorbed oxygen were shown in Figure 2. After the analysis of the physisorbed oxygen, the zinc oxide was evacuated for 30 minutes at room temperature and was followed to the thermal desorption experiment by rising the temperature. As shown in Figure 2, desorbed oxygen contains ${ }^{18} \mathrm{O}_{2}$ and ${ }^{18} \mathrm{O}^{16} \mathrm{O}$. The fraction of oxygen-18 in the desorbed oxygen decreases as increasing the desorption temperatures, and the isotopic distribution is unambiguously far from the equilibrium distribution. The mixing of oxygen-18 observed on the desorbed oxygen can be well explained by a simple replacement of the adsorbed ${ }^{16} \mathrm{O}_{2}^{-}$with ${ }^{18} \mathrm{O}_{2}$ and ${ }^{18} \mathrm{O}^{16} \mathrm{O}$ in gas phase accompanying no isotopic scramble;

$$
\begin{aligned}
& { }^{18} \mathrm{O}_{2}(g)+{ }^{16} \mathrm{O}_{2}^{-}(a) \leftrightharpoons{ }^{18} \mathrm{O}_{2}^{-}(a)+{ }^{16} \mathrm{O}_{2}(g) \\
& { }^{18} \mathrm{O}^{16} \mathrm{O}(g)+{ }^{16} \mathrm{O}_{2}^{-}(a) \leftrightharpoons{ }^{18} \mathrm{O}^{16} \mathrm{O}^{-}(a)+{ }^{16} \mathrm{O}_{2}(g) .
\end{aligned}
$$

In order to make clear the replacement of the adsorbed oxygen with gas phase one, ${ }^{18} \mathrm{O}_{2}$ of about 1 torr, having the value of ${ }^{18} \mathrm{O}{ }^{16} \mathrm{O} /\left({ }^{18} \mathrm{O}_{2}+{ }^{18} \mathrm{O}^{16} \mathrm{O}\right)$

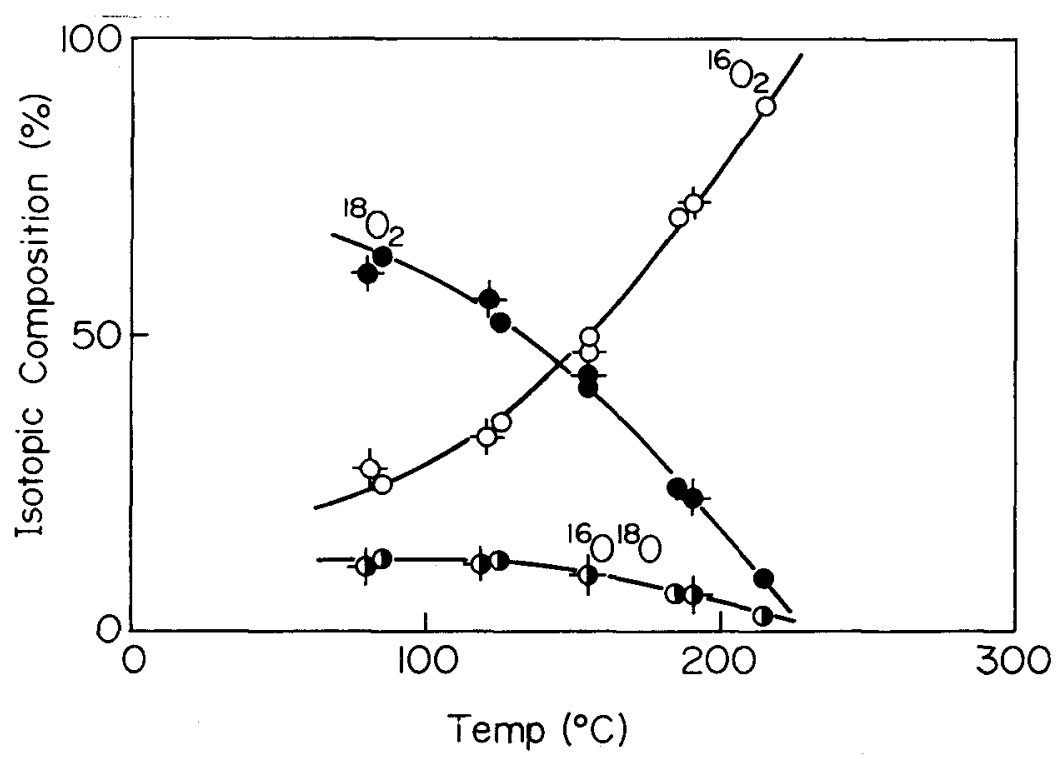

Fig. 3. Replacement of adsorbed oxygen with ${ }^{18} \mathrm{O}_{2}$ on $\mathrm{ZnO}$ at room tempeature.

, and are derived from Figure 2. 
$=0.182$, was contacted with the ${ }^{16} \mathrm{O}_{2}$ preadsorbed $\mathrm{ZnO}$ at room temperature for 5 minutes, and was evacuated for 20 minutes at room temperature.

The isotopic composition of the desorbed oxygen is shown in Figure 3, in which the values of ${ }^{18} \mathrm{O}{ }^{16} \mathrm{O} /\left({ }^{18} \mathrm{O}_{2}+{ }^{18} \mathrm{O}^{19} \mathrm{O}\right)$ are approximately equal to the valus of the ${ }^{18} \mathrm{O}_{2}$ used.

This result undoubtedly indicates that the oxygen-18 mixing in the desorbed oxygen is mainly caused by the simple replacement between the adsorbed oxygen and the gas phase oxygen.

The isotopic composition obtained in Figure 2 at the various desorption temperatures is found to give the equal distribution shown in Figure 3 as indicated with the symbols with hook.

In the previous works on the photocatalytic exchange reaction on $\mathrm{ZnO}$ and on $\mathrm{TiO}_{2}{ }^{8,9)} \mathrm{O}_{3}^{-}$species have been proposed as an intermediate of the photocatalytic exchange reaction of oxygen. The photocatalytic exchange reaction has been found to be strongly prohibited by a small amount of carbon monoxide, which has been explained by the prompt reaction of $\mathrm{CO}$ with $\mathrm{O}^{-}$species prohibiting the formation of $\mathrm{O}_{3}^{-}$, the intermediate of the exchange reaction.

In contrast with the photocatalytic exchange reaction of oxygen, the exchange reaction taking place at liquid nitrogen temperature takes few influence by $\mathrm{CO}$ addition. These results obtained in the present experiments, accordingly, reveals the new type intermediate for the low temperature isotopic mixing of oxygen. In conformity with the fact that the super oxide ions, $\mathrm{O}_{2}^{-}$, do not exchange with gas phase oxygen at liquid nitrogen temperature, the $\mathrm{O}_{4}^{-}$formed from $\mathrm{O}_{2}^{-}$and $\mathrm{O}_{2}$ should be ruled out, and a neutral $\mathrm{O}_{4}$ species may be proposed as a plausible intermediate of this low temperature exchange reaction. This result will be confirmed by using oxygen-17 and ESR technique.

\section{References}

1) J. H. Lunsford, Catalysis Rev., 8, 135 (1973).

2) K. TANAKA and G. Blyholder, Chem. Comm., 736 (1971).

K. TANAKA and G. Blyholder, J. Phys. Chem., 76, 1807 (1972).

3) K. Tanaka and G. Blyholder, Chem. Comm., 1343 (1971).

4) K. TANAKA and K. MiYahara, Chem. Comm., 877 (1973).

5) C. NACCACHE, Chem. phys. Lett., 11, 1323 (1971).

6) T. I. BARRY and F. S. Stone, Proc. Roy. Soc. (London), A 335, 124 (1960).

7) K. Hirota and M. Chono, J. Catalysis, 3, 196 (1964).

8 ) K. TANAKA, J. phys. Chem., 78, 555 (1974).

9 ) K. TANAKA and K. MiYaharA, J. phys. Chem., 78, 2303 (1974). 